\title{
Comprehensive Evaluation of the Properties of Nanocrystalline Diamond Coatings Grown Using CVD with E/H Field Glow Discharge Stabilization
}

\author{
Iu. Nasieka, ${ }^{1}$ V. Strelchuk, ${ }^{1}$ Yu. Stubrov, ${ }^{1}$ M. Boyko, ${ }^{1}$ S. Dudnik, ${ }^{2}$ \\ K. Koshevoy, ${ }^{2}$ and V. Strel'nitskij ${ }^{2}$ \\ ${ }^{1}$ V.Ye. Lashkaryov Institute of Semiconductor Physics, NAS of Ukraine, 45 Pr. Nauki, Kyiv 03028, Ukraine \\ ${ }^{2}$ National Science Center "Kharkov Institute of Physics and Technology", Akademicheskaya Street, Kharkov 61108, Ukraine \\ Correspondence should be addressed to Iu. Nasieka; yunaseka@gmail.com
}

Received 2 April 2015; Revised 16 July 2015; Accepted 21 July 2015

Academic Editor: Lili Zhang

Copyright (c) $2015 \mathrm{Iu}$. Nasieka et al. This is an open access article distributed under the Creative Commons Attribution License, which permits unrestricted use, distribution, and reproduction in any medium, provided the original work is properly cited.

The nanocrystalline diamond films (coatings) were prepared using the plasma enhanced chemical vapor deposition (PECVD) technique. In this method, direct current (DC) glow discharge in the crossed $\mathrm{E} / \mathrm{H}$ fields was used to activate the gas phase. The diamond coatings were deposited from the working gas mixture $\mathrm{CH}_{4} / \mathrm{H}_{2}$ with addition of nitrogen in various concentrations. It was ascertained that addition of $\mathrm{N}_{2}$ to the working gas mixture leads to reduction in the sizes of diamond grains as well as to the substantial decrease in the resistivity of the studied films. The electrophysical data are in good agreement with the changes induced by varying the $\mathrm{N}_{2}$ content in the Raman scattering spectra. The increase in the $\mathrm{N}_{2}$ concentration causes significant lowering of the crystalline diamond related peak and increase in the intensity of the peaks related to the $s p^{2}$-bonded carbon. These changes in the spectra indicate significant disordering of the structure of prepared films and its uniformity in the nanodiamond film volume. With the great possibility, it is associated with a decrease in the sizes of diamond crystalline grains and tendency of NCD film to amorphization.

\section{Introduction}

Previously, it was ascertained that reducing the crystallite sizes in polycrystalline diamond films causes the substantial decrease in growth of the surface roughness and induces changes of electrical, morphological, and structural and emission properties inherent to these films [1-5]. Up to date, nanocrystalline diamond (NCD) films are regarded as a new material with a high application potential in electronic and optical devices as well as medicine. In Ukraine, the works for the synthesis of NCD films are carried out in National Science Center "Kharkov Institute of Physics and Technology"; here, the deposition method and corresponding setup for diamond films deposition based on the directcurrent glow discharge in the crossed $\mathrm{E} / \mathrm{H}$ fields (chemical vapor deposition) were developed [6, 7]. Morphological and structural investigation of these diamond materials are performed in V.Ye. Lashkaryov Institute of Semiconductor Physics, NAS of Ukraine, Laboratory of Optical Submicron Spectroscopy.

One of the ways to achieve the grain refinement down to nanosizes in the diamond films prepared by chemical vapor deposition (CVD) is partial or full hydrogen substitution in the $\mathrm{CH}_{4} / \mathrm{H}_{2}$ precursor gas mixture with nitrogen. Thus, the deposition process is followed by intense secondary nucleation hindering the growth of the large diamond crystallites and holding their nanosizes even at a significant film thickness (micrometers) [8-11].

Microscopy of the cross-section in the above films indicates that under a high $\mathrm{N}_{2}$ content the columnar growth of diamond crystallites is hindered, and the grain size minimization to nanosizes in all directions occurs. It is important to note that transition from large size crystalline structure to microcrystalline and nanostructure, which is seen from 
[12-14], can be stimulated not only by changing the content of gas-precursor phase but also by bombing the surface of growing coating with ions from the gas discharge under supplying the accelerating potential to the substrate holder.

This work is aimed at detailed studies of the morphological, structural, and electrical properties of NCD films (coatings) after hydrogen substitution in the $\mathrm{CH}_{4} / \mathrm{H}_{2}$ precursor gas mixture with nitrogen during the growth process.

\section{Experimental Part}

2.1. Nanocrystalline Diamond Films Growth. In National Science Center "Kharkov Institute of Physics and Technology," the method and setup for polycrystalline diamond film deposition where activation of the gas phase is realized through the DC glow discharge in crossed E/H fields are developed and successfully used $[6,7]$. The presence of crossed magnetic field in this scheme of gas discharge leads to stabilization of the normal glow discharge in a wide range of discharge currents at the current density higher than $1 \mathrm{~A} / \mathrm{cm}^{2}$. Herewith, the power density used for activation of the working gas reaches $1000 \mathrm{~W} / \mathrm{cm}^{3}$, which corresponds to energetic characteristics typical for the high-efficient industrial equipment for synthesis of diamond coatings. Contrary to the classic scheme of glow discharge used for activation of the gas phase (where substrate holder is one of the electrodes (anode) for discharge), in the construction of developed equipment the substrate holder is electrically isolated from the anode as well as from cathode. Nevertheless, at the discharge excitation, as presented in [7], the substrate acquires the negative (floating) potential relatively to earthed anode and reaction chamber walls. The value of the potential can reach $40 \%$ from the voltage between anode and cathode and depends on discharge conditions. It results in additional bombardment of the substrate surface by plasma ions. To provide formation of nanostructured diamond coatings in the glow discharge $\mathrm{N}_{2}$ was added to $\mathrm{CH}_{4} / \mathrm{H}_{2}$ working gas mixture $\left(\mathrm{CH}_{4}\right.$ part was $\left.0.5 \%\right)$. All experiments were performed at the glow discharge current $4.5 \mathrm{~A}$, total pressure in the chamber $8 \cdot 10^{3} \mathrm{~Pa}$, and the total gas flux $300 \mathrm{~cm}^{3} / \mathrm{min}$. These parameters were constant for all diamond coatings studied in the present work. The deposition time was chosen taking into account the stipulation of the preparation of the continuous coatings without open pores.

2.2. Resistivity Measurements. In our case, conducting doped Si plates serve as substrates, which allows applying the simple two-electrode scheme for measurements. It is noteworthy that, providing the mentioned measuring scheme, it is very important to implement full contact of measuring electrode over the whole area of its touching to the surface of the film. When providing the latter, the probe electrode that contacts with the coating surface was moistened with gel electrolyte based on liquid soap. Avoiding the polarization effect at the current conduction through liquid electrolyte film on the results of resistivity measurements, the scheme with alternating current power supply was used. The measurement of Si substrate electrical resistance before deposition of coatings at different frequencies indicates that the polarization effect when the current passes through the electrolyte film has a substantial influence on results of measurements only at the frequencies lower than $10-15 \mathrm{kHz}$. Therefore, further measurements of electrical resistance inherent to the studied samples with a diamond coating were carried out at the frequency $20 \mathrm{kHz}$. The electrical resistance of substrate and electrode was equal to $30 \pm 0.5 \mathrm{Ohm}$ and taken into account when determining the electrical resistance of diamond films. The resistivity $\rho$ of diamond films was obtained using the equation $\rho=R_{\text {diam }} \cdot(S / h)$, where $h$ is the diamond film thickness and $S$ is the measuring electrode contact area. It is worth noting the following fact. The diamond film thickness was determined by the weight change per area unit during the experiment. Herewith, the film density was taken equal to the diamond one $3.5 \mathrm{~g} / \mathrm{cm}^{3}$.

2.3. Optical Characterization. The structural quality of NCD films was characterized using micro-Raman scattering ( $\mu$ RS) spectroscopy. The $\mu$-RS spectra were measured at $T=$ $300 \mathrm{~K}$ using the triple Raman spectrometer HORIBA JobinYvon T64000 equipped with a confocal microscope UVVisible-NIR Olympus BX4 for micro-Raman sampling. As an excitation tool for $\mu$-RS, the $3.82 \mathrm{eV}(325 \mathrm{~nm})$ line from He$\mathrm{Cd}$ laser was used. In this configuration, the laser spot was focused using the X100 objective to a diameter less than $1 \mu \mathrm{m}$. Morphology of the studied NCD films was investigated using the atomic-force microscope NT-206 and scanning electron microscope JSM-7001F.

\section{Results and Discussion}

Figure 1 presents SEM images of the surface of diamond films with the thickness $8-10 \mu \mathrm{m}$ prepared at various $\mathrm{N}_{2}$ concentrations. One can see that the films deposited from $\mathrm{CH}_{4} / \mathrm{H}_{2}$ mixture with $6 \%$ of $\mathrm{N}_{2}$ consist of relatively large grains with clear faceting. Increase of $\mathrm{N}_{2}$ incorporation up to $25 \%$ leads to a substantial decrease in the diamond grain sizes and to disappearance of clear faceting. As it follows from Figure 1, the microstructure of studied samples has accreted globule-like view with the sizes less than $1 \mu \mathrm{m}$, where their surface is coated with nanoscale globule-like formations. The sizes of globule-like formations and microroughness of the surface decrease when the $\mathrm{N}_{2}$ concentration in the gas mixture increases. Thus, for the coatings prepared at $6 \%$ of $\mathrm{N}_{2}$, the microroughness of the surface $R_{a}=72.2 \mathrm{~nm}$, while for the coatings prepared at $25 \%$ of $\mathrm{N}_{2}, R_{a}=32 \mathrm{~nm}$, that is, more than 2 times lower. Simultaneously, the sizes of globulelike formations are within the range 20-40 nm (Figure 2). According to the results of $\mathrm{X}$-ray diffractometry, the diamond coatings deposited from the $\mathrm{CH}_{4} / \mathrm{H}_{2}$ mixture are characterized by a block structure with the size of coherent scattering region close to $70 \mathrm{~nm}$ and unit cell parameter $a_{0}=0.3567 \mathrm{~nm}$, which is typical for natural diamond. Addition of $25 \%$ of $\mathrm{N}_{2}$ to the gas mixture leads not only to decrease in the sizes of coherent scattering region up to $25 \mathrm{~nm}$ but also to decrease in the unit cell sizes of diamond to $0.3563 \mathrm{~nm}$. 


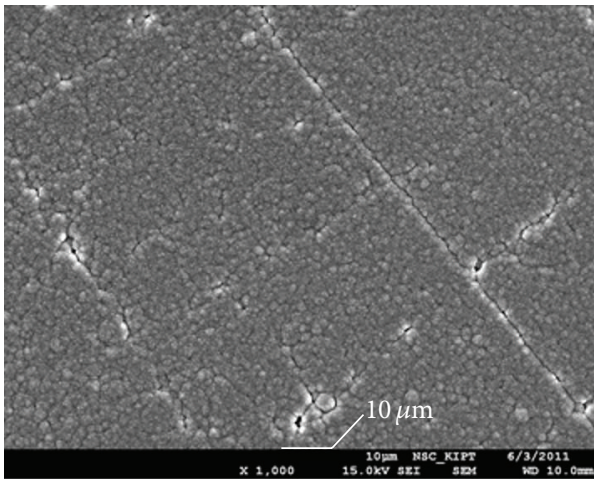

(a)

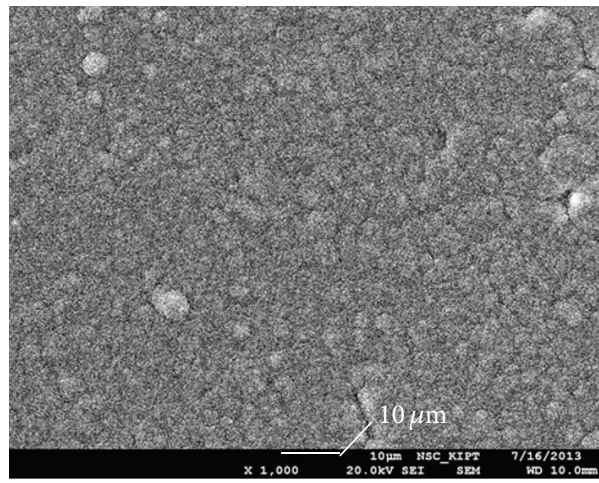

(c)

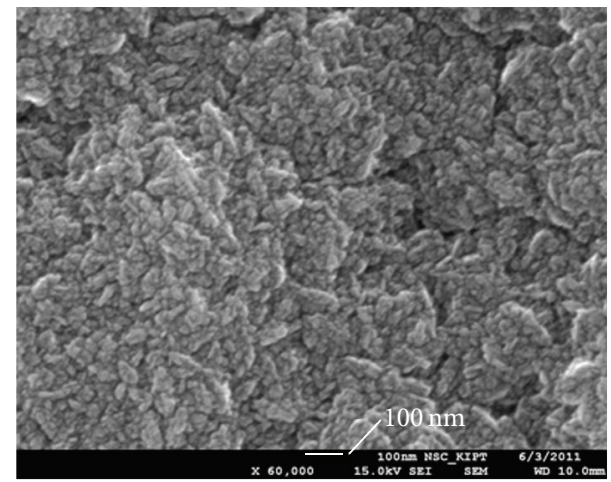

(b)

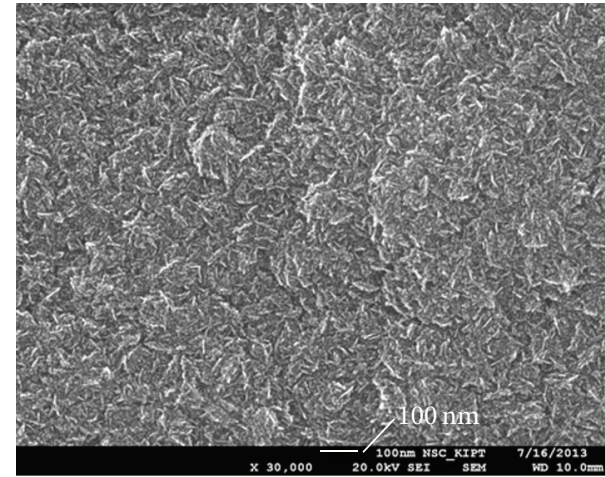

(d)

FIGURE 1: SEM images of the surface of diamond films: (a), (b) obtained for the films grown with $6 \%$ of $\mathrm{N}_{2}$ in working gas mixture; (c), (d) $25 \%$ of $\mathrm{N}_{2}$.

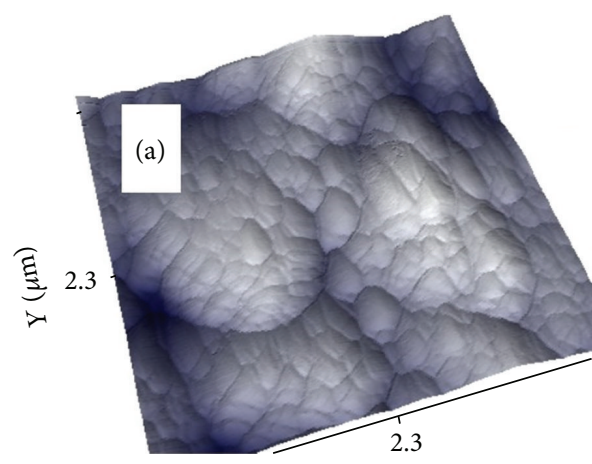

$X: 4.7 \mu \mathrm{m} Y: 4.7 \mu \mathrm{m} \mathrm{Z:} 627.9 \mathrm{~nm}[0.7: 1]$ $R_{a}: 87.8 \mathrm{~nm} R_{q}: 108.2 \mathrm{~nm}$
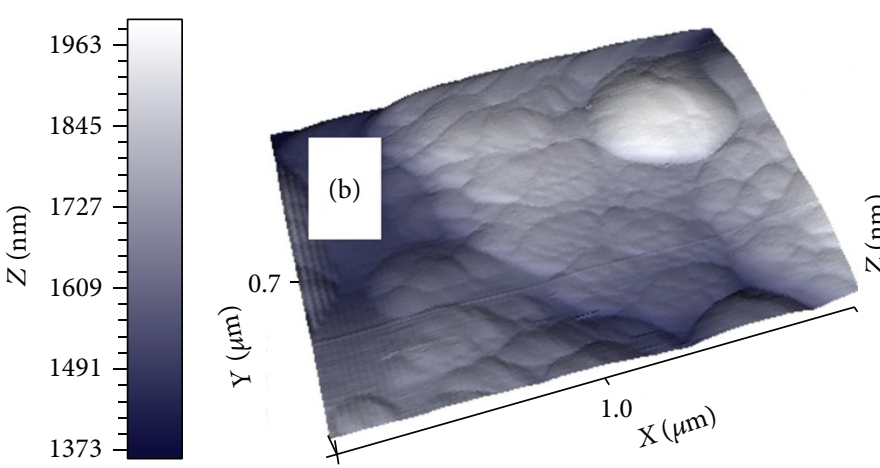

$X: 1.9 \mu \mathrm{m} \mathrm{Y:} 1.4 \mu \mathrm{m} Z: 273.4 \mathrm{~nm}[0.7: 1]$ $R_{a}: 39.6 \mathrm{~nm} R_{q}: 48.8 \mathrm{~nm}$

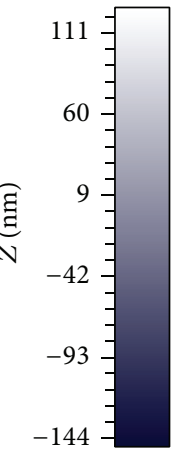

FIGURE 2: AFM images of the surface of diamond films: (a) obtained for the films grown with $6 \%$ of $\mathrm{N}_{2}$ in working gas mixture; (c) $25 \%$ of $\mathrm{N}_{2}$.

The decrease in the crystal lattice parameters in comparison with the tabulated values typical for bulk crystals is a distinctive feature of nanostructured materials.

Figure 3 shows Raman scattering spectra of NCD films grown with $12 \%$ of $\mathrm{N}_{2}$ content in gas-precursor mixture. Also, Figure 3 presents decomposition of typical spectra by elementary Lorentz and Gaussian contours. The correctness of this decomposition was proved by the curve of the sum of decomposed contours (dotted line). One can see a good agreement between the experimental and dotted lines. It is important to note that we decomposed all the obtained spectra, and further discussion operates with different spectral 


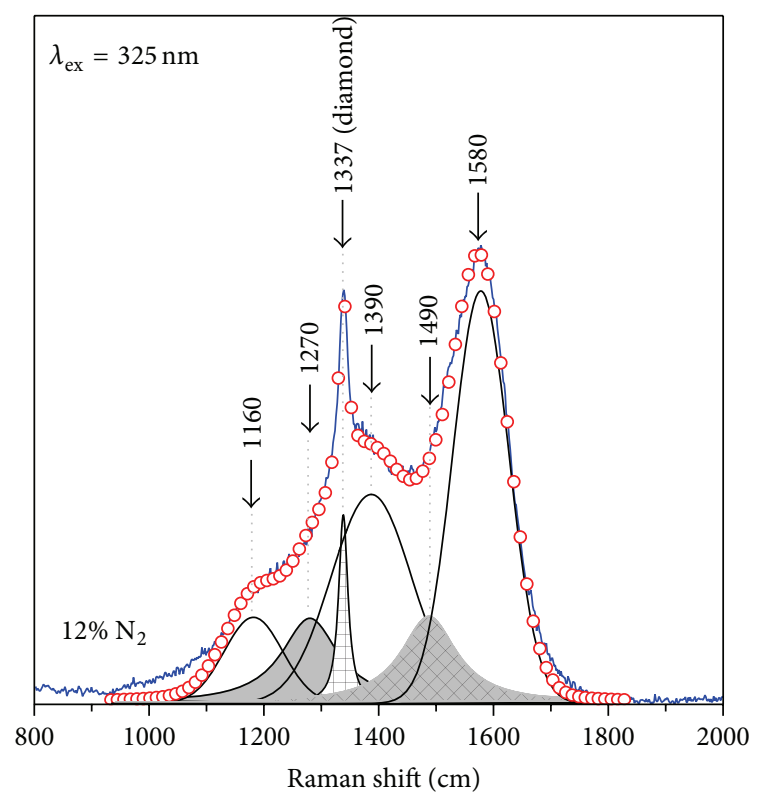

FIGURE 3: Room-temperature Raman scattering spectra registered for diamond films prepared in the plasma of glow discharge with $12 \%$ of $\mathrm{N}_{2}$ in working gas mixture. Also, decomposition on elementary contours was presented. The dotted curve is the sum of decomposed contours.

parameters based on the mentioned decomposition. Further, we did not display all the decomposed contours with the aim to prevent complications in the figures. From the specific features and decompositions in the spectra, the following phases can be identified:

(a) crystalline diamond at $1337 \mathrm{~cm}^{-1}$;

(b) $s p^{2}$-bonded carbon (disordered graphite) with $\mathrm{D}$ and $G$ peaks at $1390 \mathrm{~cm}^{-1}$ and $1580 \mathrm{~cm}^{-1}$; D line is induced by "breathing" vibrational mode of $s p^{2}$ atoms vibrations in the rings; $\mathrm{G}$ line is caused by crystalline graphite, $s p^{2}$ phase;

(c) trans-polyacetylene (t-PA) with two peaks at $1160 \mathrm{~cm}^{-1}$ (C-H in-plane bending mode) and $1490 \mathrm{~cm}^{-1}$ (CC stretch) [14-16];

(d) line at $1180-1270 \mathrm{~cm}^{-1}$ is induced by $s p^{3}$ diamond bonding in tetrahedral amorphous carbon (ta-C) [1618]; it is typical for nanocrystalline diamond.

Figure 4 displays evolution of Raman scattering spectra inherent to the studied NCD films for various $\mathrm{N}_{2}$ concentrations. One can see that the increase in the $\mathrm{N}_{2}$ concentration causes the decrease in the intensity of crystalline diamond related peak as well as lines associated with transpolyacetylene and increase in the intensity of peaks related to $s p^{2}$-bonded carbon. The shift of the positions of D and G lines towards high frequency (from 1578 to $1594 \mathrm{~cm}^{-1}$ ) with increase in the $\mathrm{N}_{2}$ concentration was registered indicating an increase in $s p^{2}$ bond angle order for trivalent carbon atoms in graphitic components. The ratio of intensities of the $\mathrm{D}$ and $\mathrm{G}$ peaks increases (from 0.5 to 0.58 ) with the $\mathrm{N}_{2}$

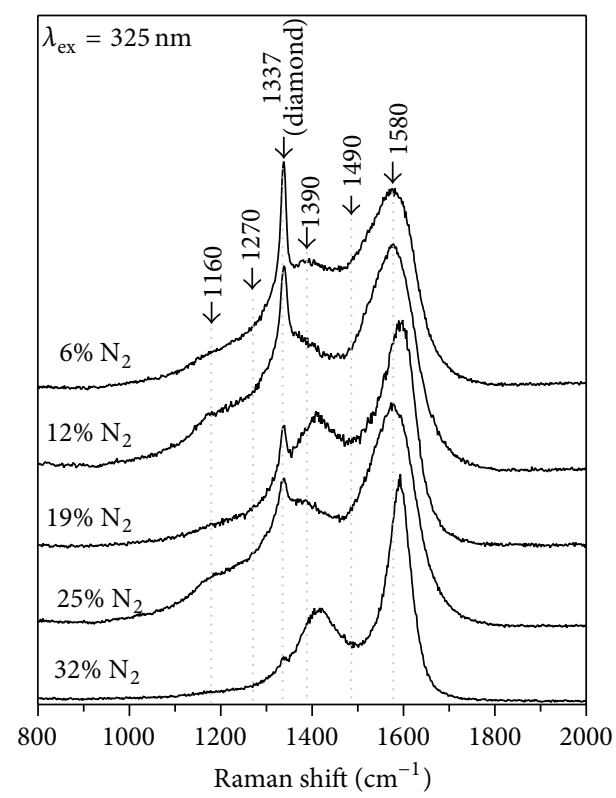

FIGURE 4: The series of room-temperature Raman spectra of PECVD NCD films deposited from gas-precursor mixtures with various $\mathrm{N}_{2}$ content. The excitation wavelength is $325 \mathrm{~nm}$.

concentration in operation gas mixture indicating a decrease in the average in-plane size graphitic components. These changes can be explained by the increase of disorder level due to the decrease in sizes of crystalline diamond grains and increase in the number of regions with $s p^{2}$-bonded carbon. Also, transformation of the well-defined peak at $1160 \mathrm{~cm}^{-1}$ to a very weak shoulder suggests an improvement of $s p^{2}$-bonded carbon in the grain boundaries of NCD films. The relative $s p^{3}$ content in grain boundaries of NCD films with various $\mathrm{N}_{2}$ concentrations can be determined using the following equation [18-24]:

$$
s p^{3} \text { content }=0.24-48.9\left(\omega_{G}-0.1580\right) .
$$

Using (1), one can determine that the increase in the $\mathrm{N}_{2}$ concentration from 6 up to $30 \%$ leads to changes in the relative $s p^{3}$ content in diamond crystalline grain boundaries from 0.25 down to 0.15 .

It is important to note that the data of Raman scattering investigation good correlates with SEM and AFM studies. For the comprehensive evaluation of the influence of the presence of $\mathrm{N}_{2}$ in operation gas mixture on the physical properties of NCD coatings the electrophysical study was performed. It is known from [22-24] that availability of $\mathrm{N}_{2}$ in the reacting gas mixture substantially influences electroconductivity of nanostructured diamond coatings. Our investigations of the dependence of diamond film electrical resistance on the $\mathrm{N}_{2}$ concentration in the gas phase were performed with the samples prepared at various $\mathrm{CH}_{4}$ concentrations $(1 \%, 1.5 \%$, and $2 \%)$. The $\mathrm{H}_{2}$ content in the gas phase depends on the total number of other components. In this work, the $\mathrm{H}_{2}$ concentration was varied from 0 up to $33 \%$. The obtained dependences are presented in Figure 5. The most significant 


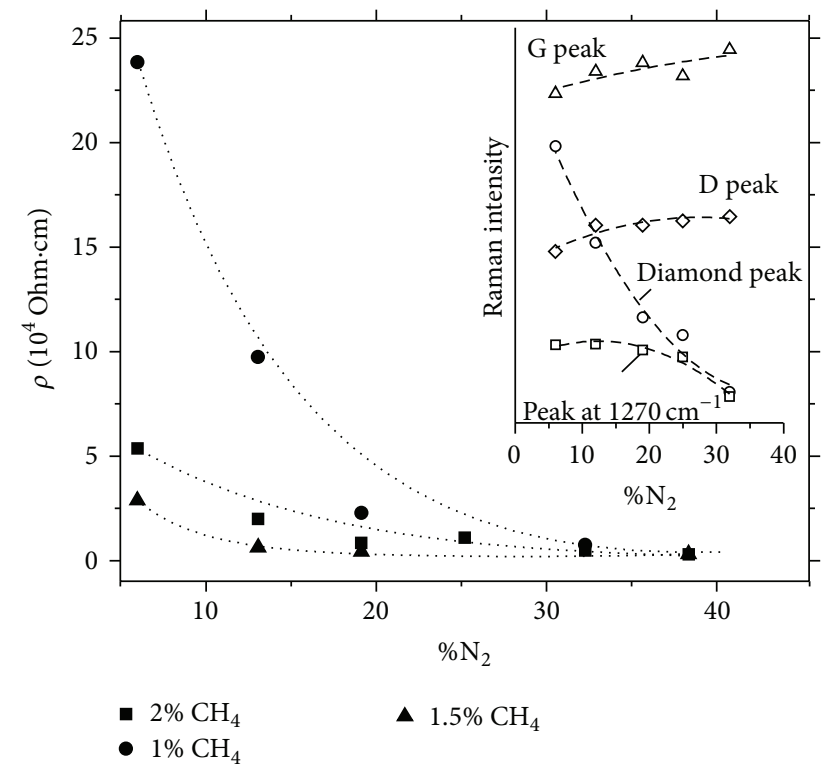

FIGURE 5: The dependence of resistivity of diamond film on the $\mathrm{N}_{2}$ concentration in the gas phase at various $\mathrm{CH}_{4}$ concentrations. With the aim to display the correlation between morphological and structural investigation data and electrophysical data, the dependence of corresponding Raman modes intensity on the $\mathrm{N}_{2}$ concentration is presented in the insertion.

decrease in the resistivity of $\mathrm{N}$-doped diamond films occurs when the $\mathrm{N}_{2}$ concentration in the gas phase increases to approximately $15-20 \%$. Upon reaching the $\mathrm{N}_{2}$ concentration $25-30 \%$ and higher, the diamond film resistivity changes insignificantly approaching the value $1.7 \times 10^{3} \mathrm{Ohm} \times \mathrm{cm}$ without any dependence on the $\mathrm{CH}_{4}$ concentration. For comparison, the diamond coating at the $\mathrm{Ar}$ concentration $60 \%, \mathrm{H}_{2} 38 \%$, and $\mathrm{CH}_{4} 2 \%$ was prepared without addition of $\mathrm{N}_{2}$ in the gas phase. The resistivity of the above film amounted to $7 \times 10^{6} \mathrm{Ohm} \times \mathrm{cm}$. The dependence of corresponding Raman modes intensity on the $\mathrm{N}_{2}$ concentration is presented in the insertion to Figure 5. One can see that the behavior of electrical resistance with the increase in $\mathrm{N}_{2}$ concentration good correlates with the behavior of the intensities of $s p^{3}$ bonded carbon related vibrational peaks. The latter can be explained by the increase in the density of the diamond crystalline grain boundaries of the amorphous nature with a higher $s p^{2}$ content. The regions with the $s p^{2}$ content have smaller resistivity and can shunt the detector volume.

\section{Conclusions}

The investigations of the influence of the $\mathrm{N}_{2}$ content in gas-precursor mixture on the morphological, structural, and electrophysical parameters of diamond coatings synthesized from $\mathrm{CH}_{4} / \mathrm{H}_{2}$ mixture in the plasma of DC glow discharge stabilized by crossed $\mathrm{E} / \mathrm{H}$ fields have been carried out. It has been ascertained that transition from coarse-crystalline diamond coatings to the small-crystalline and nanocrystalline ones occurs at $\mathrm{N}_{2}$ concentration $\sim 20 \%$. The data of morphological and structural investigations have good correlation with results of electrophysical measurements as well as AFM and SEM measurements forming the comprehensive idea relatively to the nature of the processes that occurs under feeding $\mathrm{N}_{2}$ into the reacting gas mixture. Evolution of Raman scattering spectra in the studied NCD films with increasing the $\mathrm{N}_{2}$ concentration up to $32 \%$ displays the decrease in the intensity of crystalline diamond related peak and increase in the intensity of the peaks related to $s p^{2}$-bonded carbon. These changes in the spectra indicate significant disordering of the structure of prepared films and its uniformity in the nanodiamond film volume. With a great possibility, it is associated with decreasing the sizes of diamond crystalline grains and tendency of NCD film to amorphization.

\section{Conflict of Interests}

The authors declare that there is no conflict of interests regarding the publication of this paper.

\section{References}

[1] D. M. Gruen, "Nanocrystalline diamonds films," Annual Review of Materials Science, vol. 29, no. 1, pp. 211-259, 1999.

[2] S.-M. Huang, H.-C. Hsu, M.-S. You, and F. C.-N. Hong, "Growth of diamond films with high surface smoothness," Diamond and Related Materials, vol. 15, no. 1, pp. 22-28, 2006.

[3] L. Gan, A. Bolker, C. Saguy et al., "The effect of grain boundaries and adsorbates on the electrical properties of hydrogenated ultra nano crystalline diamond," Diamond and Related Materials, vol. 18, no. 9, pp. 1118-1122, 2009.

[4] M.-S. You, F. C.-N. Hong, Y.-R. Jeng, and S.-M. Huang, "Low temperature growth of highly transparent nanocrystalline diamond films on quartz glass by hot filament chemical vapor deposition," Diamond and Related Materials, vol. 18, no. 2-3, pp. 155-159, 2009.

[5] H.-C. Chen, U. Palnitkar, B. Sundaravel, I.-N. Lin, A. P. Singh, and R. K. Ranade, "Enhancement of field emission properties in nanocrystalline diamond films upon $100 \mathrm{MeV}$ silver ion irradiation," Diamond and Related Materials, vol. 18, no. 2-3, pp. 164-168, 2009.

[6] V. K. Pashnev, V. E. Strel'nitskij, O. A. Opalev, V. I. Gritsyna, I. I. Vyrovets, and Y. A. Bizyukov, "Influence of a transverse magnetic field on the characteristics of a DC gas discharge," Plasma Physics Reports, vol. 30, no. 9, pp. 797-803, 2004.

[7] V. K. Pashnev, V. E. Strel'nitskij, O. A. Opalev, and V. A. Bilous, "Some feature of direct current glow in transverse magnetic field for diamond films deposition," in Proceedings of the 4th International Symposium on Diamond Films and Related Materials (ISDF '99), pp. 18-22, Kharkov, Ukraine, 1999.

[8] I. I. Vyrovets, V. I. Gritsyna, S. F. Dudnik, O. A. Opalev, E. N. Reshetnyak, and V. E. Strelnitskiy, "Surface morphology and structure of nanocrystalline diamond films deposited in $\mathrm{CH}_{4} / \mathrm{H}_{2} /$ Ar glow discharge plasma," Functional Materials, vol. 16, no. 2, pp. 155-160, 2009.

[9] Y.-C. Lee, S.-J. Lin, D. Pradhan, and I.-N. Lin, "Improvement on the growth of ultra-nanocrystalline diamond by using prenucleation technique," Diamond and Related Materials, vol. 15, no. 2-3, pp. 353-356, 2006. 
[10] A. J. S. Fernandes, M. A. Neto, F. A. Almeida, R. F. Silva, and F. M. Costa, "Nano- and micro-crystalline diamond growth by MPCVD in extremely poor hydrogen uniform plasmas," Diamond and Related Materials, vol. 16, no. 4-7, pp. 757-761, 2007.

[11] J. Birrell, J. E. Gerbi, O. Auciello, J. M. Gibson, J. Johnson, and J. A. Carlisle, "Interpretation of the Raman spectra of ultrananocrystalline diamond," Diamond and Related Materials, vol. 14, no. 1, pp. 86-92, 2005.

[12] A. Heiman, I. Gouzman, S. H. Christiansen, H. P. Strunk, and A. Hoffman, "Nano-diamond films deposited by direct current glow discharge assisted chemical vapor deposition," Diamond and Related Materials, vol. 9, no. 3, pp. 866-871, 2000.

[13] A. Heiman, E. Lakin, E. Zolotoyabko, and A. Hoffman, "Microstructure and stress in nano-crystalline diamond films deposited by DC glow discharge CVD," Diamond and Related Materials, vol. 11, no. 3-6, pp. 601-607, 2002.

[14] C.-C. Teng, S.-M. Song, C.-M. Sung, and C.-T. Lin, "Structural transformation upon nitrogen doping of ultrananocrystalline diamond films by microwave plasma CVD," Journal of Nanomaterials, vol. 2009, Article ID 621208, 7 pages, 2009.

[15] R. Pfeiffer, H. Kuzmany, N. Salk, and B. Günther, "Evidence for trans-polyacetylene in nanocrystalline diamond films from $\mathrm{H}$ D isotropic substitution experiments," Applied Physics Letters, vol. 82, no. 23, pp. 4149-4150, 2003.

[16] A. C. Ferrari and J. Robertson, "Origin of the $1150 \mathrm{~cm}^{-1}$ Raman mode in nanocrystalline diamond," Physical Review B, vol. 63, no. 12, Article ID 121405, 2001.

[17] I. I. Vlasov, V. G. Ralchenko, E. Goovaerts, A. V. Saveliev, and M. V. Kanzyuba, "Bulk and surface-enhanced Raman spectroscopy of nitrogen-doped ultrananocrystalline diamond films," Physica Status Solidi (A): Applications and Materials Science, vol. 203, no. 12, pp. 3028-3035, 2006.

[18] Z. Y. Chen, J. P. Zhao, T. Yano, T. Ooie, M. Yoneda, and J. Sakakibara, "Observation of $\mathrm{sp}^{3}$ bonding in tetrahedral amorphous carbon using visible Raman spectroscopy," Journal of Applied Physics, vol. 88, no. 5, pp. 2305-2308, 2000.

[19] A. Singha, A. Ghosh, A. Roy, and N. R. Ray, "Quantitative analysis of hydrogenated diamondlike carbon films by visible Raman spectroscopy," Journal of Applied Physics, vol. 100, no. 4, Article ID 044910, 2006.

[20] H. Zhou, J. Watanabe, M. Miyake, A. Ogino, M. Nagatsu, and R. Zhan, "Optical and mass spectroscopy measurements of $\mathrm{Ar} / \mathrm{CH}_{4} / \mathrm{H}_{2}$ microwave plasma for nano-crystalline diamond film deposition," Diamond and Related Materials, vol. 16, no. 47, pp. 675-678, 2007.

[21] Y. Lifshitz, X. M. Meng, S. T. Lee, R. Akhveldiany, and A. Hoffman, "Visualization of diamond nucleation and growth from energetic species," Physical Review Letters, vol. 93, no. 5, Article ID 056101, 2004.

[22] S. Bhattacharyya, O. Auciello, J. Birrell et al., "Synthesis and characterization of highly-conducting nitrogen-doped ultrananocrystalline diamond films," Applied Physics Letters, vol. 79, no. 10, pp. 1441-1443, 2001.

[23] K. L. Ma, W. J. Zhang, Y. S. Zou et al., "Electrical properties of nitrogen incorporated nanocrystalline diamond films," Diamond and Related Materials, vol. 15, no. 4-8, pp. 626-630, 2006.

[24] K. Teii and T. Ikeda, "Conductive and resistive nanocrystalline diamond films studied by Raman spectroscopy," Diamond and Related Materials, vol. 16, no. 4-7, pp. 753-756, 2007. 

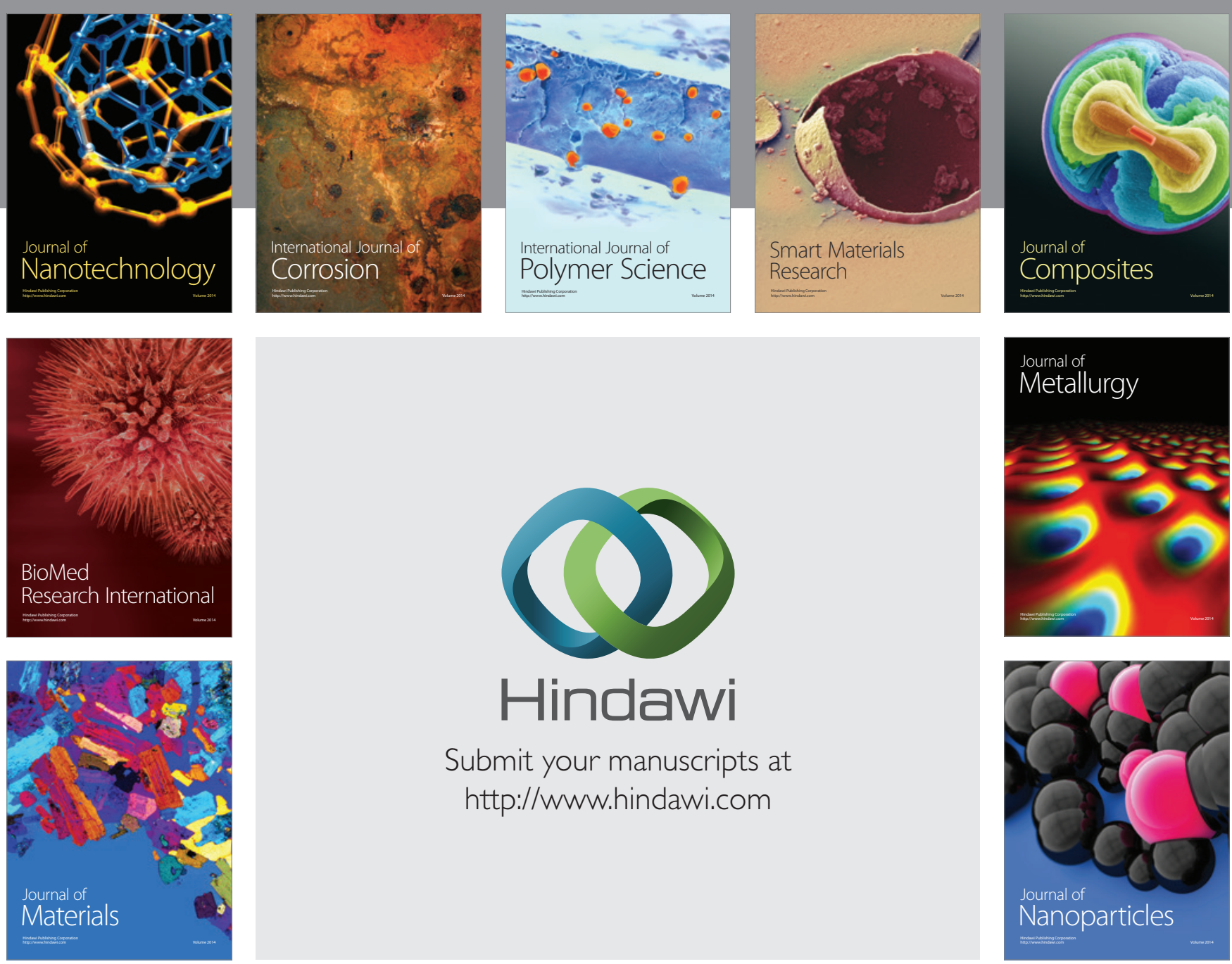

Submit your manuscripts at http://www.hindawi.com
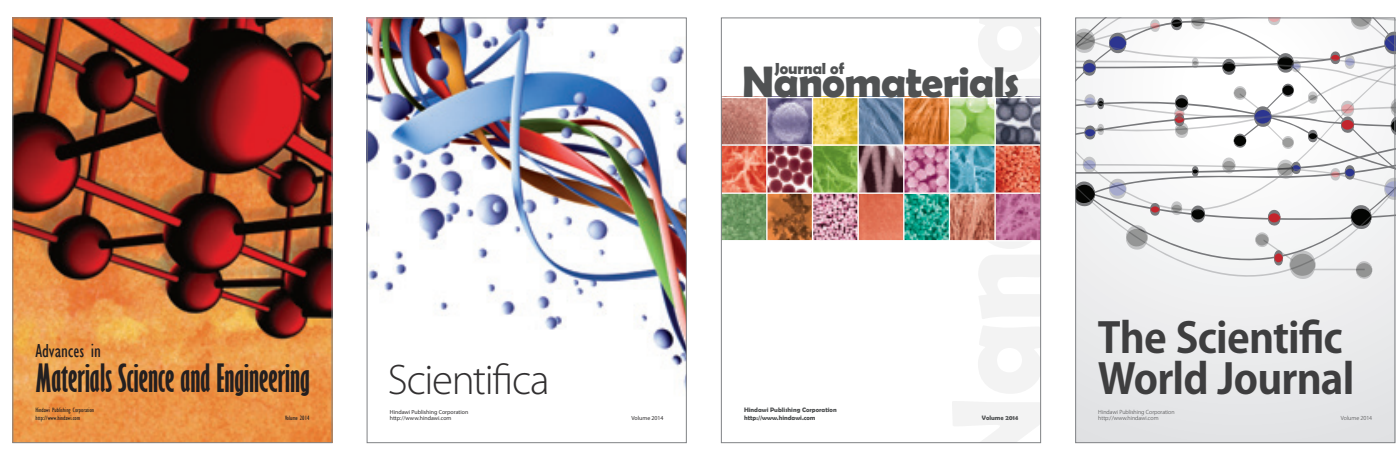

\section{The Scientific World Journal}
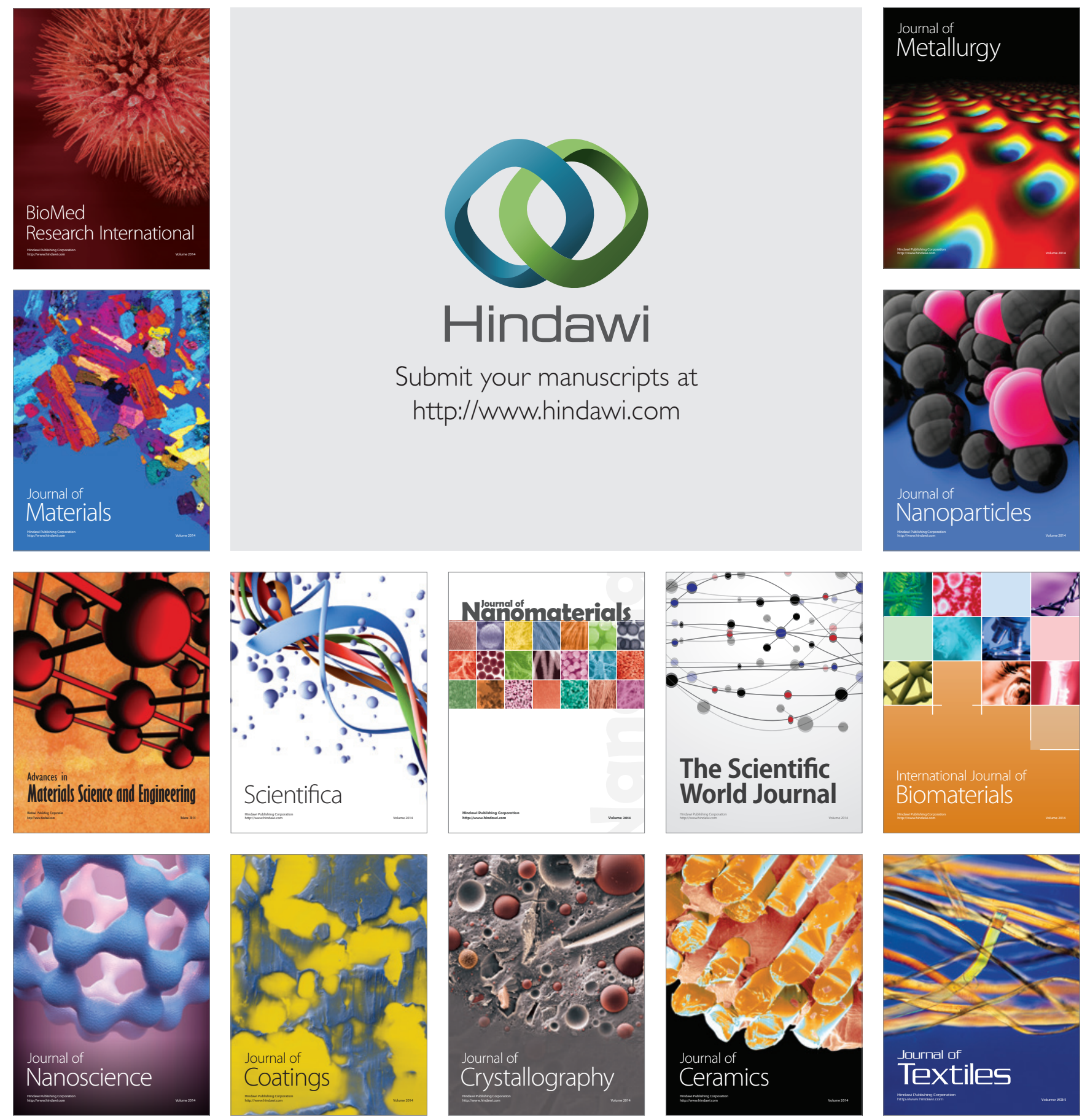